“FOCUS ON" session:

Carotid stenosis.

Epidemiology, natural history and clinical management 


\title{
Cardiovascular risk assessment using ultrasound: the value of arterial wall changes including the presence, severity and character of plaques
}

\author{
Maura Griffin², Andrew N. Nicolaides ${ }^{1,2}$, Gianni Belcaro ${ }^{3}$, Ebrahim Shah ${ }^{4}$ \\ Department of Neurovascular Sciences, The Cyprus Institute of Neurology and Genetics, Nicosia, Cyprus. \\ ${ }^{2}$ Irvine Laboratory for Cardiovascular Investigation and Research, Department of Vascular Surgery, Faculty of Medicine, Imperial College of Science, \\ Technology and Medicine, St. Mary's Hospital, London, UK. \\ ${ }^{3}$ Department of Biomedical Sciences and Cardiology School, Chieti University, Italy. \\ ${ }^{4}$ Department of Social Medicine, University of Bristol, Canynge Hall, Whiteladies Road, Bristol.
}

\begin{abstract}
Conventional cardiovascular risk factors have been used to identify subgroups at increased risk of cardiovascular events. The British Regional Heart Study Score (BRHSS) using such risk factors at best identifies only $59 \%$ of individuals that develop coronary heart disease (CHD) in the subsequent 5 years.

To identify a high risk subgroup in the BRHS a new approach has been the use of ultrasound to study arterial wall thickening, presence or absence of plaques and plaque type, to try and increase the predictive value of the BRHS Score.

Methods: Two towns (Dewsbury and Maidstone) of the British Regional Heart Study were selected because they have the highest and lowest prevalence of cardiovascular disease in the U.K respectively. A total of 418 men and 397 women were surveyed and their carotid and common femoral bifurcations scanned.

Results: Total plaque thickness, carotid intima-media thickness (IMT), ultrasonic arterial score (UAS) and sum of plaque types reversed, were found to be the most significant explanatory variables in a multiple linear regression model with an $r=0.505$ and $R 2=0.255$. They could identify a subgroup of $25 \%$ of the population that contained $78 \%$ of cardiovascular deaths.

Conclusion: These findings appear to suggest the pres-
\end{abstract}

ence of plaques, the collective information from the echomorphology of these lesions and their absolute measures are far more predictive of risk.

Copyright $(2002$ S. Karger AG. Basel

At the beginning of the 20th century, cardiovascular disease (CVD) accounted for less than 10 percent of all deaths worldwide. At its end, CVD accounted for nearly half of all deaths in the developed world and 25 percent in the developing world (World Health Report, 1999; Yusuf et al, 2001). By 2020, CVD will claim 25 million deaths annually and coronary heart disease (CHD) will surpass infectious disease as the world's number one cause of death and disability.

In an attempt to identify individuals at increased risk for premature MIs, strokes or death a number of studies have used well known conventional risk factors, such as age, smoking, raised cholesterol, or high blood pressure. These studies have followed up populations for many years and as a result have produced several risk assessment formulae or equations based on such risk factors.

The most widely used quantitative system of cardiovascular risk assessment has been the Framingham equation (Anderson et al 1990), which was developed for predicting risks of CHD, death from CHD, MI, stroke, cardiovascular disease and death from cardiovascular disease (Wilson et al, 1998). Other cardiovascular disease risk assessment tools have also been developed such as the PROCAM scoring system

Copyright @ 2002 S. Karger AG. Basel

\section{KARGER \\ Fax +41613061234 \\ E-Mail karger@karger.ch}

www.Karger.com
(๑) 2002 S. Karger AG. Basel

1424-8832/02/0326-0367\$18.50/0

\footnotetext{
Maura Griffin

Vascular Noninvasive Screening and Diagnostic Centre

28 Weymouth Street

London W1G7BZ

Tel. +44-20-73239477 - Fax +44-20-74363512

E-Mail: mauragriffin@aol.com
} 
(Assmann et al, 2002), Sheffield table system (Haq et al, 1995) and the BRHS scoring system (Shaper et al, 1987).

Although these assessment equations can provide a logical approach to stratification of risk, none are perfect and a basic problem that exists for all these scoring systems is their predictive capacity. Although these systems identify high risk groups (with a 20-30\% incidence of events), the majority of cardiovascular events occur among individuals who are not in this high risk category. For example, in the MRFIT screenees, age 35-39 followed over 16 years, 56\% of the MI's occurred among men with baseline total cholesterols between $4.1-6.2$ $\mathrm{mmol} / \mathrm{l}$ and only $14 \%$ among those with cholesterols of greater than $7.3 \mathrm{mmol} / \mathrm{l}$ (Stampfer et al, 1999).

The relatively poor specificity of these equations may be because there are still many unknown risk factors. During the last 10 years emerging risk factors such as homocysteine, nutritional disturbances, or important protective or adverse genetic risk factors that are only now being identified, and so have never been used in prospective studies on risk. Whatever the reasons, these additional patients without obvious clinical risk factors but nevertheless at increased risk should be identified before the clinical events occur. Thus, to identify subjects in the population who have an increased risk of heart attack or stroke that cannot presently be predicted is a major challenge.

Controlling some of the risk factors associated with the development of atherosclerosis has been shown to reduce clinical events in patients with established clinical disease (The Scandinavian Simvastatin Survival Study Group, 1994; Rubins et al, 1999; Sacks et al, 2000). It has been suggested that a similar effect may be found in individuals with diseased vessels who have not yet developed evidence of symptomatic atherosclerosis. In order to study such vessel changes, before the development of symptoms, a noninvasive accurate method to quantify the arterial wall changes as a result of atherosclerosis is needed thereby identifying individuals at risk. These criteria appear to have been fulfilled with the use of high-resolution Bmode ultrasound.

In recent years, the possibility of measuring vessel wall abnormalities with ultrasound has gained increasing interest. Studies of intima-media thickness, as determined by ultrasound, have been validated on autopsy studies (Pignoli et al, 1986) and animal studies (Bond et al, 1986), and these show good correlation. Ultrasound measurement of the thickness of the wall of major arteries has been shown to be feasible and reproducible (Salonen et al 1991; Persson et al, 1992; Bots, 1993; Willekes et al, 1999; Griffin and Nicolaides, 2002). In particular ultrasound methods have become frequently used in studies on progression and regression of atherosclerosis. Early stages of the disease are studied by measuring intima-media thickness (IMT), mostly at different levels of the carotid artery (Crouse et al, 1986; Pignoli et al, 1986; Salonen R et al 1988; Wendelhag et al, 1992; O'Leary et al, 1999).

By looking at arteries with ultrasound, we can see the end result of all known and unknown, environmental and genetic risk factors. The thickness of the arterial intima and media and the size and nature (stable or unstable) of cholesterol deposits or plaques can be measured objectively and noninvasively using ultrasound. Our group and others have demonstrated that these measurements are good predictors of risk.

Several studies have demonstrated that increased intimamedia thickness (IMT) of the carotid arterial wall measured with ultrasound is associated with an increased cardiovascular risk (Poli et al, 1988; Margitic et al, 1991; Salonen and Salonen, 1991; Markussis et al, 1992; Geroulakos et al, 1994).

Our group has recently shown that the main component of IMT responsible for the association with increased or decreased risk is the presence or absence of plaques (Ebrahim et al, 1999). Other natural history studies have shown the value of arterial wall measurements using ultrasound. The first was a prospective study of 2000 non-diabetic and non-hyperlipidemic individuals followed up for 6 years. It was found that the presence of plaque in the worst artery from four arteries (both common carotid and common femoral bifurcations) scanned proved to be a good predictor for risk. It was found that 59 of 217 individuals $(27 \%)$ who had at least one artery with a plaque developed an event at 6 years, whereas cardiovascular events during the follow up period were rare if plaques or intima-media thickening was absent, occurring in 10 of 1783 individuals $(0.56 \%)$. The 6 -year event rate was $18.4 \%$ for small plaques compared to $42 \%$ for large plaques producing greater than 50\% stenosis (Belcaro et al, 1996). These results were then confirmed in a second parallel study in which 10,000 individuals had been followed up for a minimum of 10 years (Belcaro et al, 2001).

In a third prospective study of 800 individuals who were part of the British Regional Heart Study (Ebrahim et al, 1999). Risk was assessed from the British Regional Heart Study Score (BRHSS). Both carotid and common femoral bifurcations were scanned with ultrasound. The total number of arteries with plaque (0-4) present, the sum of all plaque thicknesses (a measure of the severity of atherosclerosis) and the presence of echolucent plaques (echolucency is a measure of plaque instability) were found to be independent predictors of risk (Griffin and Nicolaides, 2002). These findings have now been validated on the basis of cardiovascular events at 6 years.

Ultrasonic measurements alone identified a high risk group of $25 \%$ of the population that contained $72 \%(\mathrm{p}=0.00001)$ of the cardiovascular deaths. Of the conventional risk factors, only age or the presence of diabetes was shown to improve the predictive model based on ultrasound. When age and diabetes were used in combination with the ultrasonic measurements, an even higher risk group could be identified consisting of $25 \%$ of the population that contained $78.6 \%(\mathrm{p}=0.00001)$ of the cardiovascular deaths (Griffin and Nicolaides, 2002).

It has now been demonstrated that aggressive risk factor modification is effective in preventing heart attacks and 
strokes. The CARE and LIPID studies have shown that prophylactic treatment with a lipid lowering agent taken orally (pravastatin) produces an overall $35 \%$ reduction in heart attacks and a $23 \%$ reduction of non-haemorrhagic strokes in individuals with atherosclerosis (Lewis et al, 1998; The LIPID Study Group, 1998; Byington et al, 2001). This effect is present even in the older groups and in those who have a normal cholesterol blood level, and is achieved by stabilizing atherosclerotic plaques (Crisby et al, 2001).

The results of the MRC/BHF Heart Protection Study of cholesterol lowering with simvastatin in 20,536 high risk individuals (either because of an event or because of the presence of peripheral arterial disease) but without a clear indication for cholesterol lowering therapy have demonstrated a clear benefit. This was particularly so in women, people older than 70 years, people with diabetes and those with normal or below normal cholesterol (LDL $<120 \mathrm{mg} / \mathrm{dL}$ ). (MRC/BHF Heart Protection Study Collaborative Group, 2002). Events such as heart attacks, stroke and arterial surgery were reduced by one third. Serious side effects were very rare. The observation that benefits are independent of initial lipid values raises the possibility of statin prescription without cholesterol monitoring.

Such advances in prevention research have spurred enthusiasm for primary prevention and risk assessment in asymptomatic people. Lipid-lowering trials have demonstrated that pri- mary prevention of coronary events is feasible, evidenced by the West of Scotland Coronary Primary Prevention Study (WOSCOPS) trial (Shepherd et al, 1995) of pravastatin in hypercholesterolaemic men and by the Air Force/Texas Coronary Atherosclerosis Prevention Study (AFCAPS/TexCAPS) trial events (Downs et al, 1998) that used lovastatin in average or typical risk men and women with only moderate lipid abnormalities.

For clinicians, identifying a successful strategy to target such individuals is of critical importance, but the greatest importance is in trying to identify such persons in the first instance. Arterial wall changes observed by ultrasound can be a powerful epidemiological and risk predicting tool. Ultrasound provides a noninvasive, practical and feasible screening method. Not only can it define the high risk individual, who might otherwise be classed in a moderate - low risk category from absence of clinical risk factors, but it also has the potential to develop into a test that could reassure and confirm an individual's low risk status. New guidelines on improving coronary heart disease assessment add support to the selective approach of such noninvasive testing (Smith et al, 2000; Greenland et al, 2001; Kuller, 2001; Pearson 2002). The ability to assess and stratify risk early in an individual's life could allow implementation of the most effective strategy that in turn may halt the scourge of the world's number one killer.

\section{References}

Anderson KM, Odell PM, Wilson PW, Kannel WB. Cardiovascular disease risk profiles. Am Heart J. Jan. 1990;121:293-298.

Assmann G, Cullen P, Schulte H. Simple scoring scheme for calculating the risk of acute coronary events based on the 10-year follow-up of the Prospective Cardiovascular Münster (PROCAM) Study. Circulation. 2002; 105:310-315.

Belcaro G, Nicolaides AN, Laurora G, Cesarone MR, De Sanctis M, Incandela L, Barsotti A. Ultrasound morphology classification of the arterial wall and cardiovascular events in a 6year follow-up study. Arterioscler Thromb Vasc Biol. 1996;16:851-856.

Belcaro G, Nicolaides AN, Ramaswami G, Cesarone MR, De Sanctis M, Incandela L, Ferrari P, Geroulakos G, Barsotti A, Griffin M, Dhanjil S, Sabetai M, Bucci M, Martines G. Carotid and femoral ultrasound morphology screening and cardiovascular events in low risk subjects: a 10-year follow-up study (the CAFES-CAVE study (1)). Atherosclerosis. 2001;156:379-87.

Bond GM, Ball M. Assessment of Ultrasound BMode, Imaging for Detection and Quantification of Atherosclerotic Lesions in Arteries of Animals. Report to National Institutes of Health. No NHLBI-NO I-HV12916, 1986.

Bots ML, Hofman A, de Bruyn AM, de Jong PT, Grobbee DE. Isolated systolic hypertension and vessel wall thickness of the carotid artery.
The Rotterdam Elderly Study. Arterioscler Thromb. 1993;13:64-69.

Crisby M, Nordin-Fredriksson G, Shah PK, Yano J, Zhu J, Nilsson J. Pravastatin treatment increases collagen content and decreases lipid content, inflammation, metalloproteinases and cell death in human carotid plaques. Implications for plaque stabilization. Circulation 2001;103:926-933

Downs JR, Clearfield M, Weis S, Whitney E, Shapiro DR, Beere PA, Langendorfer A, Stein EA, Kruyer W, Gotto AM Jr. Primary prevention of acute coronary events with lovastatin in men and women with average cholesterol levels: results of AFCAPS/TexCAPS. Air Force/Texas Coronary Atherosclerosis Prevention Study. JAMA. 1998;279:16151622.

Ebrahim S, Papacosta O, Whincup P, Wannamethee G, Walker M, Nicolaides A, Dhanjil S, Griffin M, Belcaro G, Rumley A, Lowe G. Carotid plaque, intima-media thickness, cardiovascular risk factors and prevalent cardiovascular disease in men and women: The British Regional Heart Study. Stroke. 1999;30:841-850.

Geroulakos G, Ramaswami G, Nicolaides A, et al. Characterisation of symptomatic and asymptomatic carotid plaques using high-resolution real-time ultrasonography. Br J Surg 1993; 80:1274-1277.

Greenland P, Smith S, Grundy S. Improving coronary heart disease risk. Assessment on
Asymptomatic People. Role of traditional risk factors and noninvasive cardiovascular tests. Circulation. 2001;104:1863-1867.

Griffin M, Nicolaides N. 2002 (In preparation)

Haq IU, Jackson PR, Yeo WW, Ramsay LE. Sheffield risk and treatment table for cholesterol lowering for primary prevention of coronary heart disease. Lancet. 1995; 346:14671471.

Heart Protection Study Collaborative Group. MRC/BHF Heart Protection Study of cholesterol lowering with simvastatin in 20,536 highrisk individuals: a randomized placebo-controlled trial. Lancet 2002;360:7-22

Kuller LH. Prevention of cardiovascular disease and the future of cardiovascular disease epidemiology. Int J Epidemiol. 2001; 30 Suppl 1:S66-72.

Lewis SJ, Moye LA, Sacks FM et al. Effect of pravastatin on cardiovascular events in older patients with myocardial infarction and cholesterol levels in the average range. Results of the CARE trial. Ann Int Med 1998;129:681-9

Margitic SE, Bond MG, Crouse JR, Furberg CD, Probstfield JL. Progression and regression of carotid atherosclerosis in clinical trials. Atheroscler Thromb 1991; 11; 443-51.

Markussis V, Beshyah SA, Fisher C, Sharp P, Nicolaides AN, Johnston DG. Detection of premature atherosclerosis by high resolution ultrasonography in symptom-free hypopituitary adults. Lancet 1992;340;1185-92

Pearson TA. New tools for Coronary Risk 
Assessment. What are their advantages and limitations? Circulation 2002; 105:886-892.

Persson J, Stavenow L, Wikstrand J, Israelsson B, Formgren J, Berglund G. Noninvasive quantification of atherosclerotic lesions. Reproducibility of ultrasonographic measurement of arterial wall thickness and plaque size. Arterioscler Thromb. 1992;12:261-266.

Pignoli P, Tremoli E, Poli A. Oreste P, Paoletti R. Intimal plus medial thickness of the arterial wall: a direct measurement with ultrasound imaging. Circulation. 1986;6:1399-1406.

Pittilo RM, Woolf N. Cigarette smoking, endothelial cell injury and atherosclerosis. J Smoking Related Disorders. 1993;4:17-25.

Poli A, Tremoli E, Colombo A, Simori M, Pignoli P, Paoletti R. Ultrasonographic measurement of the common carotid artery wall thickness in hypercholesterolemic patients: a new model for the quantification and follow-up of preclinical atherosclerosis in living human subjects. Atherosclerosis 1998; 70:253-61.

Rubins HB, Robins SJ, Collins D, Fye CL, Anderson JW, Elam MB, Faas FH, Linares E, Schaefer EJ, Schectman G, Wilt TJ, Wittes J. Gemfibrozil for the secondary prevention of coronary heart disease in men with low levels of high-density lipoprotein cholesterol. Veterans Affairs High-Density Lipoprotein Cholesterol Intervention Trial Study Group. N Engl J Med. 1999;341:410-418
Sacks FM, Tonkin AM, Shepherd J, Braunwald E, Cobbe S, Hawkins CM, Keech A, Packard C, Simes J, Byington R, Furberg CD. Effect of pravastatin on coronary disease events in subgroups defined by coronary risk factors: the Prospective Pravastatin Pooling Project. Circulation. 2000;102:1893-1900.

Salonen R, Haapanen A, Salonen JT. Measurement of intima-media thickness of common carotid arteries with high-resolution B-mode ultrasonography: inter-and intra-observer variability. Ultrasound Med Biol. 1991;17:225-230.

Salonen R, Salonen JT. Determinants of carotic intima-media thickness: a population-based ultrasonography study in Eastern Finnish men. J Int Med. 1991;229:225-231.

Scandinavian Simvastatin Survival Study group Randomised trial of cholesterol lowering in 4444 patients with coronary heart disease: the Scandinavian Simvastatin Survival Study (4S) Lancet. 1994;344:1383-1389.

Shaper AG. Pocock SJ. Phillips AN. Walker M. A scoring system to identify men at high risk of a heart attack. Health Trends. 1987;19:37-9.

Shepherd J, Cobbe SM, Ford I, Isles CG, Lorimer AR, MacFarlane PW, McKillop JH, Packard CJ. Prevention of coronary heart disease with pravastatin in men with hypercholesterolaemia. West of Scotland Coronary Prevention Study (WOSCOPS) Group. N Engl J Med. 1995;333:1301-1307.
Smith S, Greenland P, Grundy S. Prevention Conference: Executive Summary. Circulation. 2000;101:111-123.

Stamler J, Stamler R, Neaton JD et al. Low risk factor profile and long term cardiovascular and noncardiovascular mortality and life expectancy. Findings for 5 large cohort studies of young adult and middle-aged men and women. JAMA. 1999;282:2012-2018.

The LIPID Study Group. Prevention of cardiovascular events and death with pravastatin in patients with coronary heart disease and a broad range of initial cholesterol levels. N Eng J Med 1998;339:1349-5

Willekes C, Brands PJ, Willigers JM, Hoeks AP, Reneman RS. Assessment of local differences in intima-media thickness in the human common carotid artery. J Vasc Res. 1999;36:222228

Wilson PW et al. Prediction of coronary heart disease using risk factor categories. Circulation. 1998;97:1837-1847.

World Health Report 1999: Making a Difference. Geneva, World Health.

Yusuf S, Reddy S, Ônpuu S, Anand S. Global burden of Cardiovascular Diseases: Part I: general considerations, the epidemiologic transition, risk factors, and impact of urbanization. Circulation. 2001;104:2746-2753. 